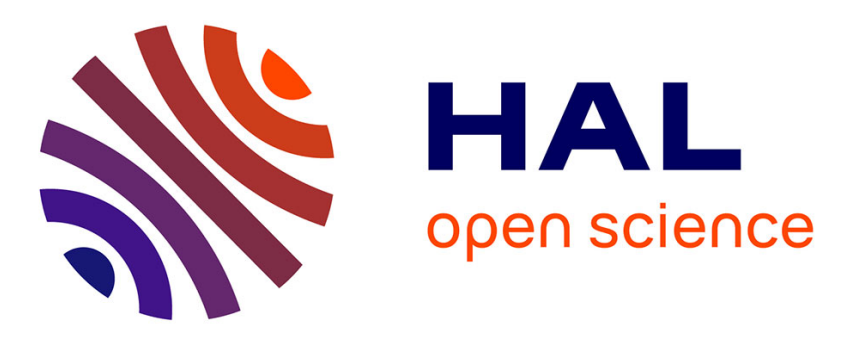

\title{
Entrapment of uropathogenic E. coli cells into ultra-thin sol-gel matrices on gold thin films: A low cost alternative for impedimetric bacteria sensing
}

Hamed Jafari, Mandana Amiri, Esmat Abdi, Saeid Latifi Navid, Julie Bouckaert, Roxana Jijie, Rabah Boukherroub, Sabine Szunerits

\section{To cite this version:}

Hamed Jafari, Mandana Amiri, Esmat Abdi, Saeid Latifi Navid, Julie Bouckaert, et al.. Entrapment of uropathogenic E. coli cells into ultra-thin sol-gel matrices on gold thin films: A low cost alternative for impedimetric bacteria sensing. Biosensors and Bioelectronics, 2019, 124-125 (11n12), pp.161-166. 10.1016/j.bios.2018.10.029 . hal-02373240

\section{HAL Id: hal-02373240 \\ https://hal.science/hal-02373240}

Submitted on 4 Dec 2020

HAL is a multi-disciplinary open access archive for the deposit and dissemination of scientific research documents, whether they are published or not. The documents may come from teaching and research institutions in France or abroad, or from public or private research centers.
L'archive ouverte pluridisciplinaire HAL, est destinée au dépôt et à la diffusion de documents scientifiques de niveau recherche, publiés ou non, émanant des établissements d'enseignement et de recherche français ou étrangers, des laboratoires publics ou privés. 


\title{
Entrapment of uropathogenic $E$. coli cells into ultra-thin sol-gel matrices on gold thin films: A low cost alternative for impedimetric bacteria sensing
}

\author{
Hamed Jafari ${ }^{\mathrm{a}}$, Mandana Amiri ${ }^{\mathrm{a}, \mathrm{e}, *}$, Esmat Abdi $^{\mathrm{b}}$, Saeid Latifi Navid ${ }^{\mathrm{b}}$, Julie Bouckaert ${ }^{\mathrm{c}}$, \\ Roxana Jijie $^{\mathrm{d}}$, Rabah Boukherroub ${ }^{\mathrm{d}}$, Sabine Szunerits ${ }^{\mathrm{d}, * *}$ \\ a Department of Chemistry, University of Mohaghegh Ardabili, Ardabil, Iran \\ b Department of Biology, University of Mohaghegh Ardabili, Ardabil, Iran \\ ${ }^{\text {c } U n i t e ́ ~ d e ~ G l y c o b i o l o g i e ~ S t r u c t u r a l e ~ e t ~ F o n c t i o n n e l l e ~(U G S F), ~ U n i v . ~ L i l l e, ~ C N R S, ~ U M R ~ 8576, ~} 59655$ Villeneuve d'Ascq, France \\ ${ }^{\mathrm{d}}$ Univ. Lille, CNRS, Centrale Lille, ISEN, Univ. Valenciennes, UMR 8520-IEMN, F-59000 Lille, France \\ e Biosensors and Bioelectronics Research Center (BBRC), Ardabil University of Medical Sciences, Ardabil, Iran
}

\section{A R T I C L E I N F O}

\section{Keywords:}

Uropathogenic E. coli

Sol-gel

Thin film

Sensing

Electrochemical impedance spectroscopy

\begin{abstract}
A B S T R A C T
Bacterial infections are causing worldwide morbidity and mortality. One way to limit infectious outbreaks and optimize clinical management of infections is through the development of fast and sensitive sensing of bacteria. Most sensing approaches are currently based on immunological detection principles. We report here on an impedimetric sensor to selectively and sensitive detect uropathogenic $E$. coli cells (E. coli UTI89) using artificial recognition sites. We show here the possibility to imprint the rod-shape structure of $E$. coli UTI 89 into ultra-thin inorganic silica coatings on gold electrodes in a reproducible manner. A linear range from to $1 \times 10^{\circ}-1 \times 10^{4}$ cfu $\mathrm{mL}^{-1}$ is obtained. With a detection limit for E. coli UTI89 below $1 \mathrm{cfu} \mathrm{mL}^{-1}$ from five blank signals (95\% confidence level) and excellent selective binding capabilities, these bacterial cell imprinted electrodes brings us closer to a low cost specific bacterial recognition surfaces.
\end{abstract}

\section{Introduction}

Specific and sensitive detection of pathogenic microorganisms remains a scientific challenge and a problematic of high importance (Dye, 2014). Pathogen diagnosis is currently based on microorganism culturing on agar plates, being however often too long and consequently inadequate in hospital settings. Biochemical assays, molecular techniques and immunological-based methods have been proposed as alternatives (Law et al., 2014). The heterogeneous distribution and low concentration of pathogens remain challenging for these methods with detection limits of $10^{4}$ to $10^{5}$ colony forming units per milliliter (cfu/ $\mathrm{mL}$ ) (Wang and Salazar, 2016). Thus the need for the development of more rapid and less laborious methods becomes an urgent matter. Immobilization of pathogen bioreceptors such as antibodies onto conductive transducers proved of particular advantage for a fast, selective and quantitative read out (Amiri et al., 2018). Besides being costly, antibody based sensing devices lack the stability required to detect pathogenic species in harsh environmental conditions. There are currently no adequate solutions that allow the selective and sensitive binding to specific microorganism, that are fast in detection and screening, cheap to implement, and able to be conceptualized for a wide range of biologically relevant targets.

The main objective of this work is to develop a pathogen detection strategy that does not require expensive biological affinity agents and can be tailored at will to any microorganism with minimal change in the technological approach. We demonstrate here that imprinting E. coli cells into ultra-thin sol-gel film coatings allows for impedimetric pathogen detection with biologically relevant detection limits. Compared to imprinting into polymers where cross-linkers are needed (Schirhagl et al., 2010), the formation of thin imprinted organosilicate films with good diffusional penetration, important for sensing driven applications, is generally easier to achieve. Since the pioneering studies of Carturan et al. (2004) who encapsulated $S$. cerevisiae yeast cells into silica gel films and studied its catalytic activity, imprinting of whole cells into inorganic sol-gel matrices rather than polymers (Haupt, 2003) has become a widely proposed approach (Avnir et al., 2005; Eleftheriou et al., 2013; Fazal et al., 2017). These matrices have gained more interest lately for the creation of sensing devices (Borovicka et al., 2013; Chen et al., 2016). Next to porosity, nanometer-thick films are required (Kraus-Ophir et al., 2014) to allow efficient recapture of bacteria. In

\footnotetext{
* Corresponding author at: Department of Chemistry, University of Mohaghegh Ardabili, Ardabil, Iran

** Corresponding author.

E-mail addresses: mandanaamiri@uma.ac.ir (M. Amiri), sabine.szunerits@univ.lille1.fr (S. Szunerits).
} 

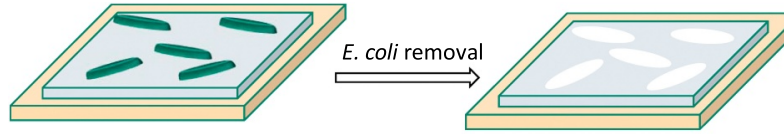

Sol-gel imprinted E. coli

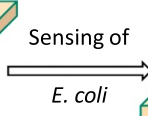

E. coli

\section{Sol-}

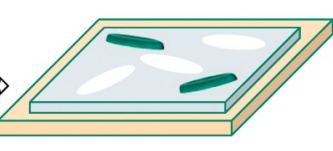

Sol-gel imprinted E. coli

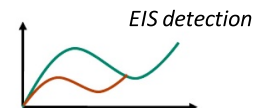

Scheme 1. Schematic steps of sol-gel imprinting bacteria on $\mathrm{Au}$ interface preparation, removal and sensing. this work, we show that sol-gel imprinted E. coli films are also adapted for rapid and selective pathogen detection (Scheme 1).

\section{Experimental}

\subsection{Materials}

Tetraethoxysilane (TEOS), (3-mercaptopropyl)trimethoxysilane (MTMS) and (3-aminopropyl) triethoxysilane (ATES) were purchased from Sigma-Aldrich and used as received. Acetic acid, ethanol, hydrochloric acid ( $\mathrm{HCl})$, cetyl trimethyl ammonium bromide (CTAB), sodium dodecyl sulfate (SDS) were obtained from Merck.

\subsection{Bacterial growth conditions}

Escherichia coli UTI89 (wild-type strain) was used for imprinting. The cells were grown in $\mathrm{LB} / \mathrm{BHUI}$ broth at $37^{\circ} \mathrm{C}$ for $18-20 \mathrm{~h}$ with shaking at $150 \mathrm{rpm}$ to reach an OD $600 \mathrm{~nm}$ of $0.6-1$. The harvested cells were washed twice to remove the culture medium and then re-suspended by vortex for $7 \mathrm{~min}$ in $10 \mathrm{~mL}$ LC/MS Grade Water (Merck, Darmstadt, Germany) to reach $1 \times 10^{8} \mathrm{cfu} \mathrm{mL}^{-1}$. S. aureus and Pseudomonas aeruginosa bacteria were grown in the same manner.

\subsection{Imprinting of E. coli into organosilica films}

The sol was prepared by mixing TEOS $(1.83 \mathrm{~mL})$ with MTMS $(0.17 \mathrm{~mL})$ in $1 \mathrm{~mL}$ of water followed by gently stirring for $10 \mathrm{~min}$ at room temperature. $\mathrm{HCl}(0.1 \mathrm{M}, 0.25 \mathrm{~mL})$ was added and the sol was stirred for $3 \mathrm{~h}$, stored in ice and used soon after preparation. Bacteria imprinting was achieved by mixing fresh sol stock solution $(0.5 \mathrm{~mL})$ with fresh aqueous bacterial suspension $\left(3 \mathrm{~mL}, 10^{8}-10^{9} \mathrm{cfu} \mathrm{mL}^{-1}\right)$ and stirring for $2 \mathrm{~min}$.

Gold coated glass slides were prepared by thermal evaporation of $5 \mathrm{~nm}$ of titanium and $50 \mathrm{~nm}$ of gold. Gold thin film electrodes were cleaned by subsequent washing in ethanol/acetone $(1 / 1)$ for $15 \mathrm{~min}$, distilled water and dried at $80^{\circ} \mathrm{C}$ for $3 \mathrm{~h}$. The cleaned electrodes were immersed vertically into the sol and removed after $30 \mathrm{~s}$ using a removal rate of $150 \mathrm{~cm} \mathrm{~min}^{-1}$ using a monitorized micromanipulator. Gelation occurred upon heating the interface at $40^{\circ} \mathrm{C}$ for $8 \mathrm{~h}$.

\subsection{E. coli removal}

The imprinted $E$. coli cells were removed from the dried films by rinsing the coated slides for $10 \mathrm{~min}$ in ethanol (70\%) and washing with sterile double-distilled water two times. Thereafter, the surface was immersed into a solution of СТАВ (2.5\%) and further rinsing for $10 \mathrm{~min}$ with double-disstilled water.

\subsection{Characterization}

Scanning Electron Microscopy (SEM): SEM images were obtained using an electron microscope ULTRA 55 (Zeiss, France) equipped with a thermal field emission emitter and three different detectors (EsB detector with filter grid, high efficiency In-lens SE detector and EverhartThornley Secondary Electron Detector).

UV/Vis measurements: Absorption spectra were recorded using a Perkin Elmer Lambda UV-Vis 950 spectrophotometer in a 1-cm quartz cuvette. The wavelength range was $200-1100 \mathrm{~nm}$.

SPR instrumentation: The surface plasmon resonance instrument used was an Autolab ESPRIT instrument (Eco Chemie, Utrecht, The Netherlands) working at $670 \mathrm{~nm}$ (Kooyman et al., 1991; Wink et al., 1998).

Profilometry: An optical profilometer (Zygo NewView 6000 Optical Profilometer with MetroPro software) with $1 \mathrm{~nm}$ height resolution was used for thickness measurements.

\subsection{Electrochemical measurements}

Electrochemical measurements were performed with an Autolab 20 potentiostat (Eco Chemie, Utrecht, The Netherlands). A conventional three-electrode configuration was employed using a silver wire and a platinum mesh as reference and auxiliary electrodes, respectively.

EIS experiments were carried out in an aqueous solution of a mixture of $10 \mathrm{mM} \mathrm{Fe}(\mathrm{CN})_{6}{ }^{4-} / 10 \mathrm{mM} \mathrm{Fe}(\mathrm{CN})_{6}{ }^{3-}$ in PBS $(0.01 \mathrm{M})$ using the following parameters: amplitude of $10 \mathrm{mV}$ at open circuit potential with a frequency range of $100 \mathrm{kHz}-0.1 \mathrm{~Hz}$. Impedance data were modeled using ZView2 software.

\section{Results and discussion}

\subsection{Imprinting of E. coli cells into ultra-thin sol gel films on gold electrodes}

A two-step sol-gel process is used for $E$. coli imprinting: a first low $\mathrm{pH}$ hydrolysis of a mixture of TEOS and MTMS, followed by neutral condensation-gelation step. MTMS was chosen as additive as the thiol function present in the sol-gel can promote the adhesion of the hydrophilic gel to the gold thin film electrode resulting in high quality layers. The thickness of the sol-gel film depends strongly on the sol-gel

Table 1

Influence of sol-gel precursor concentrations, dip time and immersion/removal time of gold interface on film thickness and charge transfer.

\begin{tabular}{|c|c|c|c|c|c|c|}
\hline TEOS (mL) & MTMS (mL) & Dip time (Sec) & Immersion/removal rate $\left(\mathrm{mm} \mathrm{min}^{-1}\right)$ & $\mathrm{d}_{\mathrm{SPR}}(\mathrm{nm})$ & $d_{\text {prof. }}(n m)$ & $\mathrm{R}_{\mathrm{CT}} \mathrm{k} \Omega$ \\
\hline 0.92 & 0.08 & 30 & 150 & $10 \pm 1$ & $9 \pm 2$ & $12.746 \pm 0.345$ \\
\hline 0.92 & 0.08 & 60 & 150 & $31 \pm 2$ & $34 \pm 3$ & $18.732 \pm 0.567$ \\
\hline 0.92 & 0.08 & 30 & 200 & $11 \pm 1$ & $13 \pm 2$ & $12.45 \pm 0.5678$ \\
\hline 0.92 & 0.08 & 60 & 200 & $30 \pm 2$ & $29 \pm 2$ & $17.235 \pm 0.675$ \\
\hline 1.83 & 0.17 & 30 & 150 & $66 \pm 1$ & $68 \pm 3$ & $202.816 \pm 0.342$ \\
\hline 1.83 & 0.17 & 60 & 150 & $96 \pm 2$ & $94 \pm 4$ & $391.548 \pm 0.345$ \\
\hline
\end{tabular}

$\mathrm{d}_{\mathrm{SPR}}$ : thickness form SPR measurements; $d_{\text {prof. }}$ thickness determined from profilometer measurements; 
(A)

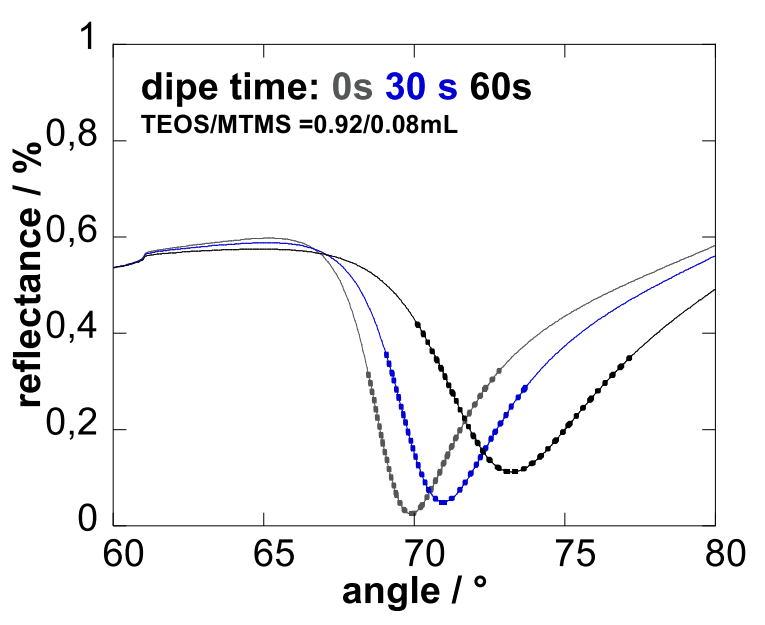

(B)

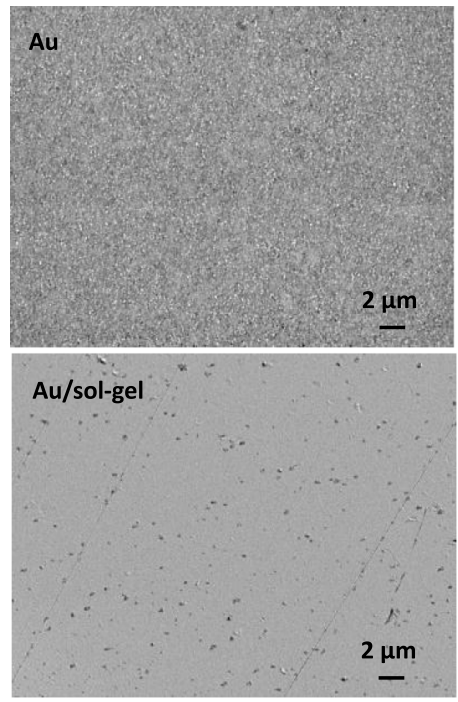

Fig. 1. (A) SPR curves of a gold electrode before (gray) and after coating with a sol-gel film upon dipping into TEOS/MTMS (0.92/ $0.08 \mathrm{~mL}$ ) for $30 \mathrm{~s}$ (blue) and $60 \mathrm{~s}$ (black) using a removal rate of $150 \mathrm{~mm} \mathrm{~cm}^{-1}$, full lines: fitted SPR curves $(\mathrm{n}=1.52, \lambda=670 \mathrm{~nm}$, $\mathrm{n}_{\mathrm{Ti}}=2.36+\mathrm{i} 3.47, \quad \mathrm{~d}_{\mathrm{Ti}}=5 \mathrm{~nm}, \quad \mathrm{n}_{\mathrm{Au}}=0.197$ $+\mathrm{i} 3.67, \mathrm{~d}_{\mathrm{Au}}=50 \mathrm{~nm}, \mathrm{n}_{\text {sol-gel }}=1.42+\mathrm{i} 0.022$ ), dotted lines: experimental curves; (B) SEM images of a gold surface before and after coating with TEOS/MTMS $(0.92 / 0.08 \mathrm{~mL})$ for $30 \mathrm{~s}$; (C) Nyquist plots of a gold interface (before, dip time $0 \mathrm{~s}$ ) and after coating with TEOS/ MTMS $(0.92 / 0.08 \mathrm{~mL})$ for $30 \mathrm{~s}$ (blue) and $60 \mathrm{~s}$ (black) (For interpretation of the references to color in this figure legend, the reader is referred to the web version of this article.).

(C)
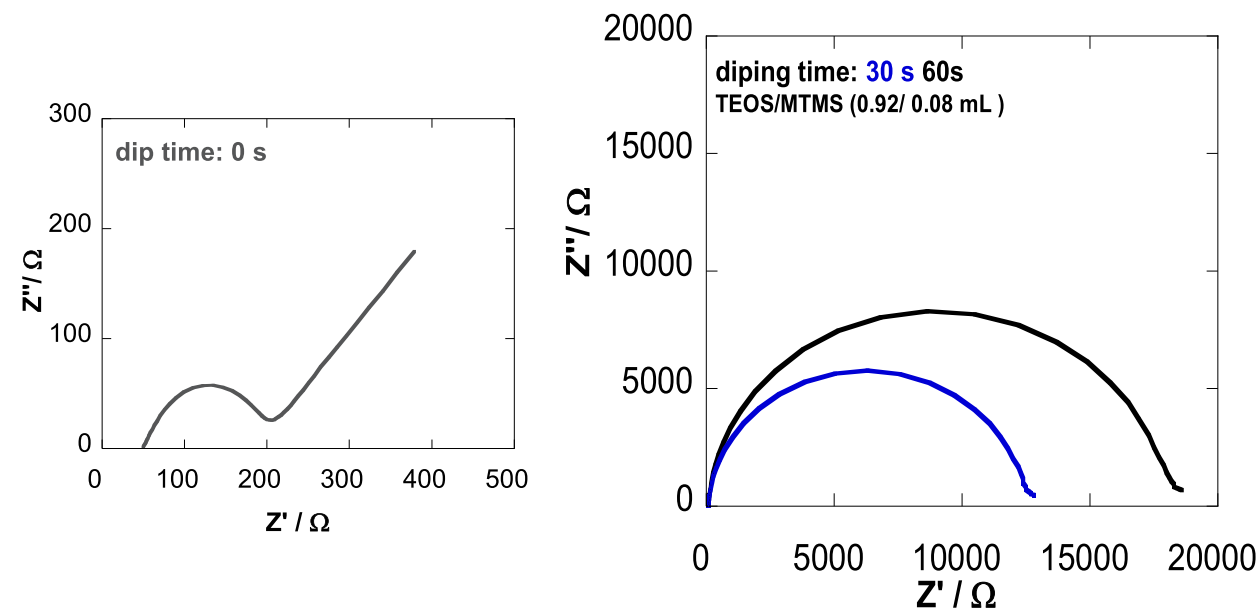

precursor concentrations, the length of dipping time of the gold thin electrode into the solution and removal rate of the electrode out of the sol (Table 1).

The concentration of TEOS/MTMS was most influencing the film thickness. Using a volume ratio of TEOS/MTMS of $1 / 0.09 \mathrm{~mL}$ and dipping the clean Au interface for $30 \mathrm{~s}$ into a fresh sol solution results in optimal sol-gel films of $10 \pm 1 \mathrm{~nm}$, as determined from shifts in the surface plasmon resonance angle and the reflectance intensity compared to a pure gold thin film (Fig. 1A). The silica film thickness determined by surface plasmon resonance is in good agreement with that obtained by profilometric measurements (Table 1 ).

The deposition of a thin sol gel film onto the gold electrode results in a very smooth surface morphology (Fig. 1B) when compared to bare gold with a visible granular surface structure. The Nyquist plots of the sol-gel coated gold electrodes upon immersion in TEOS/MTMS (0.92/ $0.08 \mathrm{~mL}$ ) for 30 or $60 \mathrm{~s}$ in the presence of $\mathrm{Fe}(\mathrm{CN})_{6}{ }^{4-/ 3-}$ as redox probe (Fig. 1C) display a semi-circle located in the high frequency range, which corresponds to a parallel $R_{\mathrm{CT}} / / C_{\mathrm{dl}}$ element due to the charge transfer resistance at the modified electrode/solution interface and the necessity to charge the double layer capacitance $C_{\mathrm{dl}}$ of this interface. While both interfaces show comparable electrolyte resistance $\left(\mathrm{R}_{\text {ele }}=50 \Omega\right)$, increasing the immersion time from 30 to 60 s results in increased charge transfer resistance. Bacteria imprinting was consequently performed using condition 1 (Table 1), which insured that the film thickness is indefinitely thin compared to the morphology of E. coli, rod shaped bacteria of approximately $500 \mathrm{~nm}$ in width and $2000 \mathrm{~nm}$ in length. Fig. 2A depicts the SEM images of the bacteria imprinted films obtained by mixing E. coli UTI89 $\left(1 \times 10^{8} \mathrm{cfu} \mathrm{mL}^{-1}\right)$ with a freshly prepared TEOS/MTMS $(0.92 / 0.08 \mathrm{~mL})$ sol and using a dipping time of $30 \mathrm{~s}$ with immersion and removal rate of $150 \mathrm{~mm} \mathrm{~cm}^{-1}$. The bacteria are coated within the thin sol-gel film with preservation of the bacteria structures. Clustering of bacteria imprinting is observed in most cases with individual bacteria being attached to each other. This might be due to a partial repulsion effect between the negatively charged bacteria and the sol-gel with no evident phase separation (Shen et al., 2014). Bacterial removal was achieved by sonicating the electrodes in ethanol (70\%), known to be most effective against microbial killing followed by immersion into SDS/acetic acid (5\%) and further sonicated for $10 \mathrm{~min}$. SDS, an anionic detergent leads to the disintegration of bacteria cell walls (Li et al., 2013); both SDS and acetic acid (Bjarnsholt et al., 2015) are known for their antimicrobial effect and to eradicate bacterial biofilms. A representative SEM image of the interface after bacteria removal is seen in Fig. 2B. Tailor-made cavities were left on the surface which can be easily accessible for bacterial binding. The removal of the $E$. coli template results in a significant decrease of the charge transfer from $22 \mathrm{k} \Omega$ (imprinted film) to $5.6 \mathrm{k} \Omega$ after removal (Fig. 2C). Without E. coli, the generation of imprinted cavities increased the electron transfer and decreased the diameter of the semicircle of 
(A)

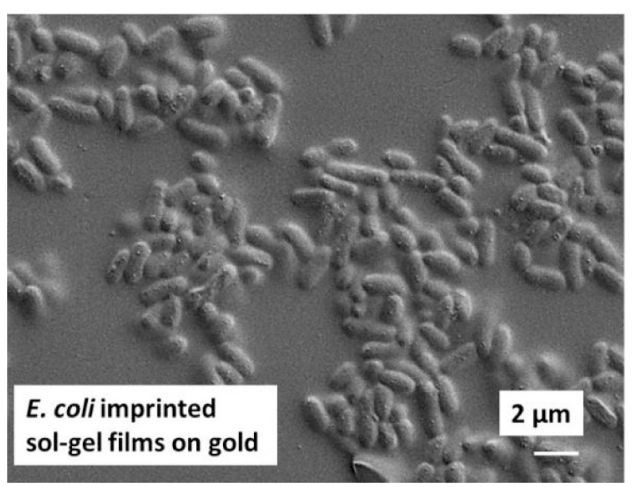

(B)

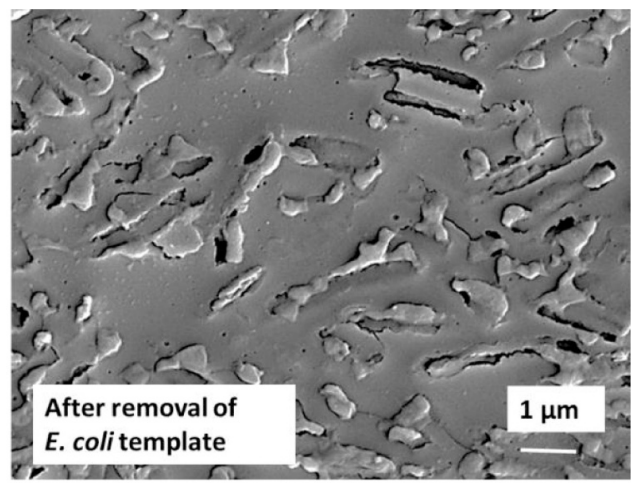

(C)

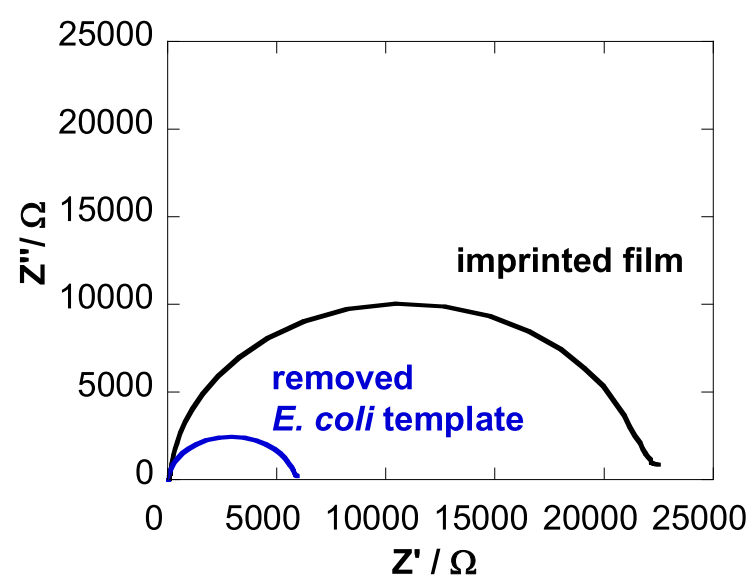

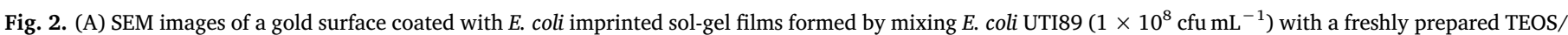

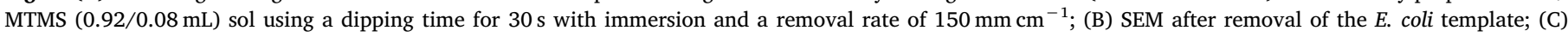

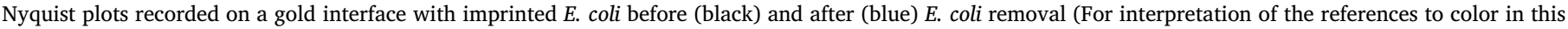
figure legend, the reader is referred to the web version of this article.).

EIS. Subsequently, when E. coli was captured, impedance of the electrode had an apparent enhancement because bacteria filled the cavities (Chen et al., 2017).

\subsection{Recognition performance of the E.coli templated electrode}

The recognition performance of the imprinted interface was studied in the following using $E$. coli UTI89 as well as $S$. aureus as negative control. Fig. 3A shows that upon incubation with different $E$. coli concentrations, the charge transfer resistance increases. As seen from the calibration curve in Fig. 3B, where the change in the charge transfer resistance Z"-Z" vs. log [E. coli UTI89] is plotted, with $\mathrm{Z}_{\mathrm{o}}$ " being the initial charge transfer resistance in the absence of pathogens, a linear range from to $1 \times 10^{0}-1 \times 10^{4} \mathrm{cfu} \mathrm{mL}^{-1}\left(\mathrm{R}^{2}=0.998\right)$ according to $\mathrm{Z}$ " $(\mathrm{k} \Omega)=1.53+3.21 \times \log [$ E.coli $]\left(\mathrm{cfu} \mathrm{mL}^{-1}\right)$ is obtained. The system displays a detection limit for $E$. coli UTI89 below $1 \mathrm{cfu} \mathrm{mL}^{-1}$ from five blank signals ( $95 \%$ confidence level). The performance of the developed impedimetric $E$. coli sensor is several orders of magnitude lower than other impedimetric sensors using anti-E. coli antibodies as sensing element (Chowdhury et al., 2012; Escamilla-Gómez et al., 2009; Maalouf et al., 2007). The sensor is also comparable to the detection limit to the BACTEC 9240 blood culture system, one of automated, continuous-monitoring systems that is widely used in clinical laboratories reaching a detection limit of $10 \mathrm{cfu} \mathrm{mL}^{-1}$ (Miller et al., 2011).

The specificity of this electrode architecture for the sensing of $E$. coli
UTI89 is evidenced in Fig. 3C, where the addition of $S$. aureus to the imprinted interface results in strongly reduced signal change. The same was true for Pseudomonas aeruginosa, also a rod shaped Gram-positive bacterium. The good selective binding towards the rod-shaped $E$. coli over the spherical $S$. aureus bacterial cells makes this approach an effective way to produce specific bacterial recognition surfaces.

The reproducibility of the imprinting process for $E$. coli UTI89 detection expressed in terms of the relative standard deviation, was determined to be $2.7 \%$ (Fig. 3D) testing an E. coli concentration of $100 \mathrm{cfu} \mathrm{mL}^{-1}$. Long-term stability of the bacteria cell imprinted electrode is insured due to the lack of bioreceptors used as recognition element. Indeed, after 1-month storage in room temperature, the loss in bacteria sensing capability was $1.1 \%$.

\subsection{Detection of E. coli UTI89 in real samples}

The potential of this sensing interface for determination of $E$. coli UTI89 levels in urine spiked with $E$. coli UTI at different concentrations was finally investigated. Urinary tract infections (UTIs) represent the most common bacterial infectious diseases for humans, with $E$. coli UTI89 the most predominant pathogens responsible for $30-50 \%$ of hospital acquired and $80-90 \%$ of community-acquired UTIs (Ejrnaes et al., 2011). Fig. 4 compares the difference in the impedimetric signal for when urine was spiked with different concentrations of $E$. coli UTI89 compared to the electrochemical signal in PBS based solutions 
(A)

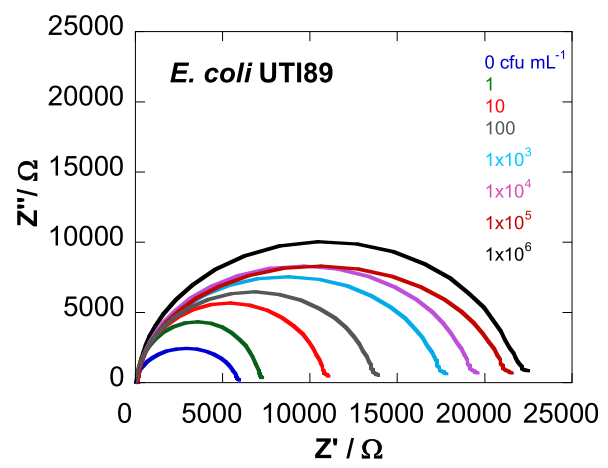

(C)

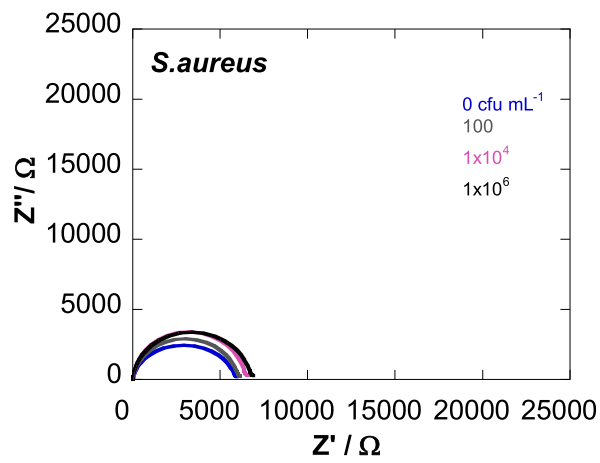

(B)
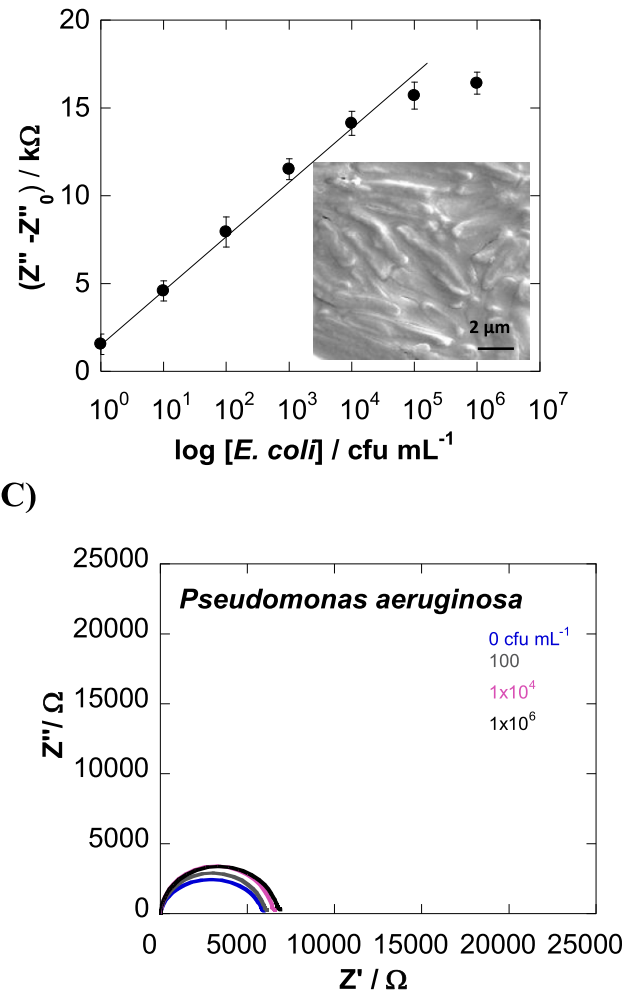

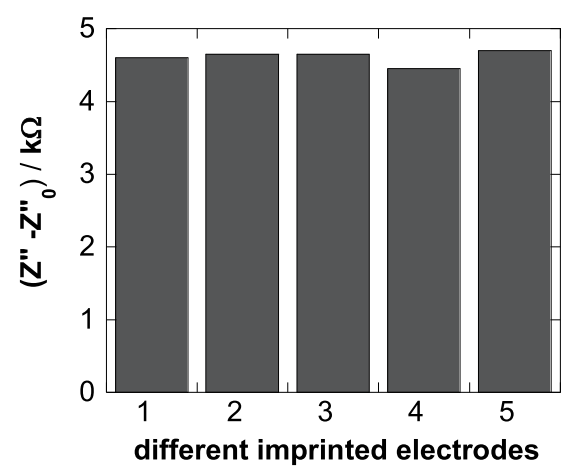

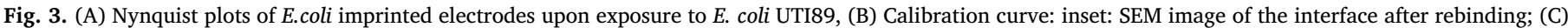

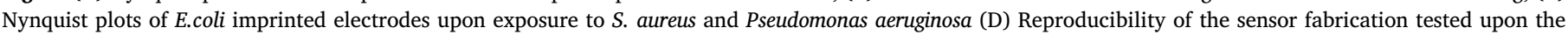
incubation with $100 \mathrm{cfu} \mathrm{mL}^{-1}$ E. coli UTI89.

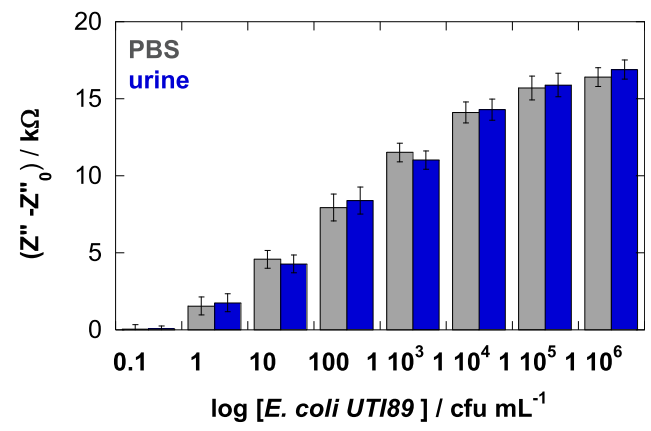

Fig. 4. (A) Comparison between the impedimetric change of E. coli UTI89 in PBS (gray) and when analyzed in urine (blue) (For interpretation of the references to color in this figure legend, the reader is referred to the web version of this article.). containing of the same concentrations. The differences are within the error of the analysis technique, pointing towards the possibility to analyze real samples with the developed sensor.

\section{Conclusion}

In summary, surface imprinting of $E$. coli bacteria cells within TEOS and MTMS derived sol-gels has been demonstrated. The artificial recognition sites formed on the electrical interfaces allow a selective and highly sensitive detection of rod-shaped bacteria cells as exemplified here with detect uropathogenic E. coli cells (E. coli UTI89). Comparing the cross sensitivity to other bacterial cells of different shape gave a good evidence about the imprinting dependent interactions between bacterial cells and the imprinted matrix. The date presented demonstrate a truly alternative to biological recognition layers such as antibodies for bacteria detection. The obtained detection limit of 
$1 \mathrm{cfu} \mathrm{mL}^{-1}$ E. coli UTI89 in urine is highly encouraging and adapted to clinical settings, where bacterial culturing methods are still mainly used, which cannot reach such detection limits in a short time span. Furthermore, the concept can be easily adapted to other pathogen species, making the approach very versatile. While tested for $E$. coli UTI89, the sensor is not specific to only to $E$. coli strain but responses to any other $E$. coli strains.

\section{Acknowledgements}

The authors gratefully acknowledge the support of this work by University of Mohaghegh Ardabili Research Council, Ardabil, Iran. Financial support from the Centre National de la Recherche Scientifique (CNRS), the University of Lille, the Hauts-de-France region, the CPER "Photonics for Society", and the joint support of Agence Nationale de la Recherche (ANR) through FLAG-ERA JTC 2015-Graphtivity project is acknowledged.

\section{References}

Amiri, M., Bezaatpour, A., Jafari, H., Boukherroub, R., Szunerits, S., 2018. Electrocehmical Methodologies for the detection of pathogens. ACS Sens. 3, 1069-1086.

Avnir, D., Coradin, T., Levc, O., Livage, J., 2005. Recent bio-applications of sol-gel materials. J. Mater. Chem. 16, 1013-1030.

Bjarnsholt, T., Alhede, M., Jensen, P.Ø., Nielsen, A.K., Johansen, H.K., Homøe, P., Høiby, N., Givskov, M., Kirketerp-Møller, K., 2015. Antibiofilm properties of acetic acid. Adv. Wound Care 4, 363-372.

Borovicka, J., Stoyanov, S.D., Paunov, V.N., 2013. Nanoscale 5, 8560.

Carturan, G., Dal Toso, R., Boninsegna, S., Dal Monte, R., 2004. Encapulsation of functinal cells by sol-gel silica: actuial progress and perspectives for cell therapy. J. Mater. Chem. 14, 2087-2098.

Chen, L., Wang, X., Lu, W., Wu, X., Li, J., 2016. Moleuclar imprinting: perspectivs and applications. Chem. Soc. Rev. 45, 2137-2211.

Chen, S., Chen, X., Zhang, L., Gao, J., Ma, Q., 2017. Electrochemiluminescence detection of Escherichia coli O157: H7 based on a novel polydopamine surface imprinted polymer biosensor. ACS Appl. Mater. Interfaces 9 (6), 5430-5436.
Chowdhury, A.D., De, A., Chaudhuri, C.R., Bandyopadhyay, K., Sen, P., 2012. Label free polyaniline based impedimetric biosensor for detection of E. coli O157:H7 bacteria. Sens. Actuator B 171-172, 916-923.

Dye, C., 2014. After 2015: infectious diseases in a new area of health and development. Philos. Trans. R. Soc. B 369, 20130426.

Ejrnaes, K., Stegger, M., Reisner, A., Ferry, S., Monsen, T., Holm, S.E., Lundgren, B., Frimodt-Moller, N., 2011. Characteristics of Escherichia coli causing persistence or relapse of urinary tract infections. Virulence 2, 528-537.

Eleftheriou, N.M., Ge, X., Kolesnik, J., Falconer, S.B., Harris, R.J., Khursigara, C., Brown, E.D., Brennan, J.D., 2013. Chem. Mater. 25, 4798.

Escamilla-Gómez, V., Campuzano, S., Pedrero, M., Pingarrón, J.M., 2009. Gold screenprinted-based impedimetric immunobiosensors for direct and sensitive Escherichia coli quantisation. Biosens. Bioelectron. 24, 3365-3371.

Fazal, Z., Pelowitz, J., Johnson, P.E., Harper, J.C., Brinker, C.J., Jakobsson, E., 2017. Three-dimensional encapsulation of asccharomyces cerevisiae in silicate matrices creats disting metabolic states as revealed by gene chip analysis. ACS Nano 11, 3560-3575.

Haupt, K., 2003. Chem. Commun. 171-178.

Kooyman, R.P.H., Lenferink, A.T.M., Eenik, R.G., Greve, J., 1991. Anal. Chem. 63, 83.

Kraus-Ophir, S., Witt, J., Wittstock, G., Mandler, D., 2014. Nanoparticle-imprinted polymers for size-selective recognition of nanoparticles. Angew. Chem. Int. Ed. 53, 294-298.

Law, J.W.-F., Mutalib, N.-S.A., Chan, K.-G., Lee, L.-H., 2014. Rapid methods for the detection of foodborne bacterial pathogens: principles, applications, advantages and limitations. Front. Microbiol. 5, 770.

Li, L., Molin, S., Yang, L., Ndoni, S., 2013. Sodium dodecyl sulfate (SDS)-loaded nanoporous polymer as anti-biofilm surface coating material. Int. J. Mol. Sci. 14, 3050-3064.

Maalouf, R., Fournier-Wirth, C., Coste, J., Chebib, H., Sarkali, Y., Vittori, O., Errachid, A., Cloarec, J., Martelet, C., N, J.-R, 2007. Label-free detection of bacteria by dlectrochemical impedance spectroscopy: comparison to surface plasmon resonance. Anal. Chem. 79, 4879-4886.

Miller, N.S., Rogan, D., Orr, B.L., Whitney, D., 2011. Comparison of BD BACTEC ${ }^{\mathrm{TM}}$ plus blood culture media versus VersaTREK ${ }^{\oplus}$ REDOX blood culture media for detection of bacterial pathogens in simulated adult blood cultures containing therapeutic concentrations of antibiotics. J. Clin. Microbiol.

Schirhagl, R., Lieberzeit, P.A., Dickert, F.L., 2010. Adv. Mater. 22, 2078.

Shen, X., Bonde, J.S., Kamra, T., Bulow, L., Leo, J.C., Linke, D., Ye, L., 2014. Bacterial imprinting at pickering emulsion interfaces. Angew. Chem. Int. Ed. 53, 10687.

Wang, Y., Salazar, J.K., 2016. Culture-independent rapid detection methods for bacterial pathogens and toxins in food matrices. Compr. Rev. Food Sc. Food Saf. 15, 183-205.

Wink, T., Van Zuilen, S.J., Bult, A., Van Bennekom, W.P., 1998. Anal. Chem. 70, 827. 